\title{
Glucose Production Rate in Extremely Immature Neonates ( $<28$ Weeks) Studied by Use of Deuterated Glucose
}

\author{
A. SUNEHAG. U. EWALD. A. LARSSON, AND J. GUSTAFSSON
}

Lppsala L'niversity' Children's Hospital. Lppsala. Sweden

\begin{abstract}
Neonatal hypoglycemia is a frequent complication in immature infants. This may be due to small substrate stores, a high brain:body weight ratio, and immature enzyme systems. The purpose of the present study was to investigate the rate of glucose production in newborn infants with gestational ages of less than 28 wk. The subjects were 10 newborn infants delivered after 25 to 26 gestational wk. Their mean birth weight was $772 \mathrm{~g}$ (range 588-1000 g), and their mean postnatal age at the time of the study was $15 \mathrm{~h}$ (range 4-24 h). An isotopic compound (D-6,6- ${ }^{2} \mathrm{H}_{2}$-glucose) was given as a constant-rate i.v. infusion. In addition to dideuteroglucose, eight of the infants also received an i.v. infusion of unlabeled glucose at a rate of $1.4-2.6 \mathrm{mg} \cdot \mathrm{kg}^{-1} \cdot \mathrm{min}^{-1}$. Blood samples for determination of the concentration and isotopic enrichment of plasma glucose were obtained every $15 \mathrm{~min}$ in a 2 -h period. Isotopic enrichment, measured by gas chromatography/mass spectrometry, was used for calculating the glucose production rate. The mean glucose production rate related to body weight $( \pm \mathrm{SD})$ was $6.1 \pm 1.5 \mathrm{mg} \cdot \mathrm{kg}^{-1} \cdot \mathrm{min}^{-1}$. The results show that infants born at $<28$ gestational wk have a capacity to produce glucose on their $1 \mathrm{st} d$ of life at rates close to or even exceeding those reported in term infants. (Pediatr Res 33: 97-100, 1993)
\end{abstract}

\section{Abbreviations}

GPR, glucose production rate

$\mathrm{CV}$, coefficient of variation

$\mathrm{Ra}$, rate of appearance

The transition from intrauterine to extrauterine life is accompanied by major alterations in fuel homeostasis. During pregnancy, the fetus is continuously supplied with glucose and amino acids from the mother. After birth. this transport of nutrients is interrupted, and the child has to mobilize fuel to meet the metabolic demands from vital organs, especially the brain. The immediate postpartum time is associated with hormonal changes, which stimulate glycogenolysis and gluconeogenesis (1). In a term newborn infant, the glycogen stores are depleted in about $10 \mathrm{~h} \mathrm{(2).} \mathrm{After} \mathrm{this,} \mathrm{the} \mathrm{glucose} \mathrm{production} \mathrm{is} \mathrm{dependent}$ on gluconeogenesis from precursors such as pyruvate, lactate, glycerol, and alanine. Defects in glucose regulation, leading to hypoglycemia, are common in immature and growth-retarded infants as well as in infants of diabetic mothers $(1,3)$. Possible

Received March 9. 1992: accepted September 15. 1992.

Correspondence and reprint requests: Jan Gustafsson M.D. Ph.D. Uppsala University Children's Hospital, 75185 Uppsala Sweden.

Supported financially by the Swedish Medical Research Council (project 4792). the Samaritan Foundation, the Sven Jerring Foundation, the Expressen Prenatal Foundation, and the Allmänna BB Foundation. causes of such regulatory defects are a high brain:body weight ratio, small substrate stores, immature enzyme systems, or excessive insulin secretion. In addition, hyperglycemia, probably due to a persistent hepatic glucose production in spite of glucose infusion, is often seen in immature infants $(4,5)$.

Knowledge of the production and utilization of substrates in newborn infants, especially those in risk groups, is of great importance in the prevention and treatment of hypoglycemia. The glucose production in term and moderately immature infants has been studied by use of glucose labeled with stable isotopes (4-8). Results of such studies have indicated that immaturity and a low birth weight may be associated with a low rate of glucose production $(6,7)$. It has also been shown that the GPR is almost linearly related to body weight (6), birth weight (8), gestational age (8), and brain weight (6). On the basis of these findings, it has been suggested that, in the presence of a glucose infusion, extremely immature infants may have virtually no glucose production (8).

The purpose of the present study was to determine whether extremely immature infants, with gestational ages of less than 28 wk, are capable of producing glucose in the first $24 \mathrm{~h}$ postnatally. Glucose labeled with deuterium was used for the investigations.

\section{SUBJECTS AND METHODS}

Subjects. The subjects of this study were 10 newborn infants. born after 25 to 26 completed gestational wk (Table 1). All of them were delivered at the University Hospital in Uppsala. Sweden, and were admitted to the neonatal intensive care unit. The study was approved by the Human Ethics Committee of the Medical Faculty of the University of Uppsala. Parental consent was obtained after oral and written information.

The gestational age of the infants was estimated from the mothers' menstrual history and confirmed by ultrasound examinations during pregnancy and by physical characteristics according to the methods of Finnström (9) and Dubowitz ot al. (10). All of the infants had birth weights appropriate for gestational age. Four of the infants (nos. 1, 5, 6, and 9) were delivered vaginally after spontaneous labor not responding to $\beta$-sympathomimetic therapy (Bricanyl, Draco, Lund. Sweden), and the other six were delivered by cesarean section (nos. 2-4. 7.8, and $10)$. The reason for cesarean section was toxemia resistant to treatment with an $\alpha$ - and $\beta$-blocking agent (Trandate. Glaxo. Greenford, England) in two cases (nos. 2 and 4 ) and premature rupture of the membranes and a poor progress of labor in two cases (nos. 3 and 10). One of these mothers (no. 3) had received $\beta$-sympathomimetic therapy (Bricanyl) at the start of labor. but the treatment had no effect and was discontinued. Two of the infants (twins, nos. 7 and 8) were delivered by cesarean section because of prolapse of the umbilical cord.

The infants were studied at a mean postnatal age $( \pm$ SD) of $14.9 \pm 5.9 \mathrm{~h}$ (Table 1) and were nursed in incubators (AGA MK 241. AGA Medical, Lidingö. Sweden) with a relative ambient 
Table 1. Patient characteristics*

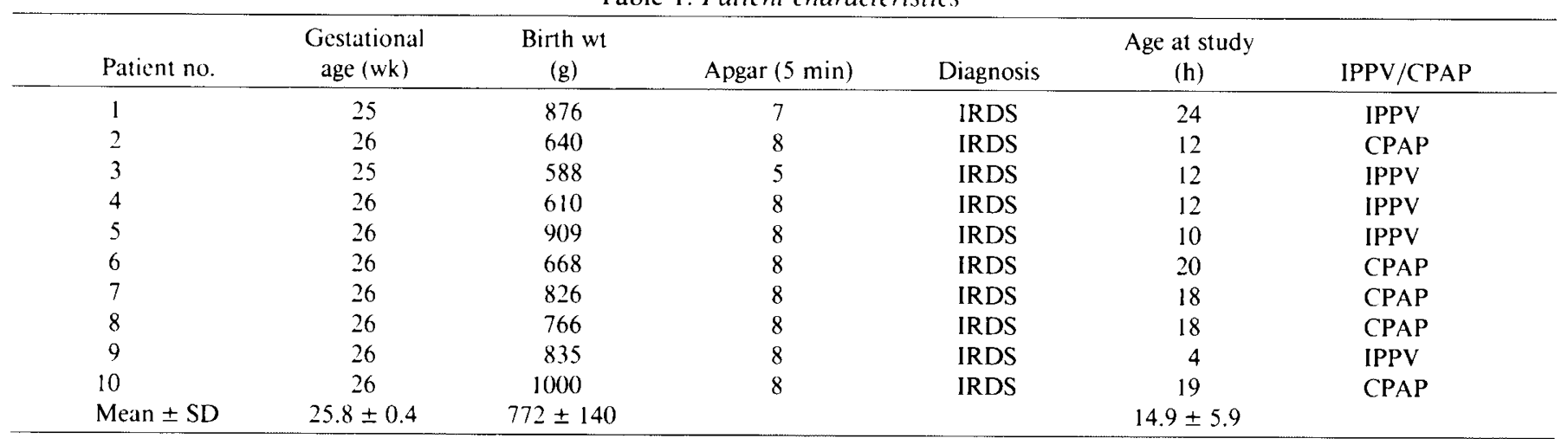

*IRDS, infant respiratory distress syndrome: IPPV, intermittent positive-pressure ventilation; CPAP, continuous positive-pressure ventilation.

humidity of $90 \%$. Their body temperatures varied between 36.9 and $37.2^{\circ} \mathrm{C}$ during the study. All of the infants were normoventilated and normoxemic. Theophylline (Teofyllamin, Kabi Vitrum, Stockholm, Sweden) $\left(6 \mathrm{mg} \cdot \mathrm{kg}^{-1} \cdot \mathrm{d}^{-1}\right)$ was administered as apnea prophylaxis in the children treated with continuous positive airway pressure (Table 1). All infants received $10 \%$ i.v. glucose infusion directly after birth, and they were also given breast milk ( $1-2 \mathrm{~mL}$ every $2 \mathrm{~h}$ ) from the age of 2 to $4 \mathrm{~h}$ (Table 2). The total volume of fluid given during the first $24 \mathrm{~h}$ was 65 $\mathrm{mL} \cdot \mathrm{kg}^{-1}$. The mean total volume of breast milk given before the study $( \pm \mathrm{SD})$ was $2.9 \pm 2.5 \mathrm{~mL}$ (Table 2$)$. The lactose content in $1 \mathrm{~mL}$ of breast milk is about $70 \mathrm{mg}$ (11).

Methods. The tracer used was D-6,6- ${ }^{2} \mathrm{H}_{2}$-glucose (isotopic purities of two different batches were 92.5 and 97.5 atom \%), purchased from MSD Isotopes, Montreal, Canada. The deuterated glucose, dissolved in $0.9 \%$ saline solution in concentrations of 1.7 and $4.5 \mathrm{mg} \cdot \mathrm{mL}^{-1}$, was pyrogen-free when tested by the Limulus lysate method (12) and was sterile in microbiologic cultures.

After a priming dose of deuterated glucose $\left(5 \mathrm{mg} \cdot \mathrm{kg}^{-1}\right.$ given in $10 \mathrm{~min})(8)$ the $6.6-{ }^{2} \mathrm{H}_{2}$-glucose solution was administered into a peripheral vein at a constant rate with a calibrated volumetric pump (IMED 965 micro, IMED, Oxford, England). The infusion rate corresponded to $0.11-0.15 \mathrm{mg} \cdot \mathrm{kg}{ }^{-1} \cdot \mathrm{min}^{-1}$ in nine patients and $0.23 \mathrm{mg} \cdot \mathrm{kg}^{-1} \cdot \mathrm{min}^{-1}$ in one patient (no. 3) (Table 2).

In addition to the isotopic compound, an infusion of unlabeled glucose was given in eight of the patients at a rate corresponding to $1.4-2.6 \mathrm{mg} \cdot \mathrm{kg}^{-1} \cdot \mathrm{min}^{-1}$ (Table 2 ). The other two patients (nos. 5 and 6) were only given deuterated glucose. Thus, the rate of glucose administration during the study was lower than that given before the study (i.e. $\sim 4.5 \mathrm{mg} \cdot \mathrm{kg}^{-1} \cdot \mathrm{min}^{-1}$ ).

Umbilical artery catheters, inserted for clinical purposes, were used for blood sampling. For determination of the concentration and isotopic enrichment of plasma glucose, blood samples (250 $\mu \mathrm{L}$ ) were drawn at the onset of the dideuteroglucose infusion and then every $15 \mathrm{~min}$ for $2 \mathrm{~h}$. The blood samples were collected into ice-cold EDTA tubes, and the plasma was immediately separated by centrifugation. Plasma glucose concentrations were measured by the glucose oxidase-peroxidase method in a glucose analyzer, Ames Minilab 1 (Bayer AG, Leverkusen, Germany) with prefilled cuvettes (Ames Minipac Gluc). When duplicate plasma glucose values obtained with this instrument were compared with corresponding values obtained with YSI 23 AM glucose analyzer (Yellow Springs Instrument Co., Yellow Springs, $\mathrm{OH})$, the limits of agreement between the two methods calculated according to Bland and Altman (13) was $-0.15 \pm 0.89$ $\mathrm{mM}$ (mean difference $\pm 2 \mathrm{SD}$ ). For Minilab 1 , the $\mathrm{CV}$ (SD/ mean) for 10 consecutive determinations were $3.4,4.8,4.3$, and $3.5 \%$ for plasma glucose concentrations of $1.2,2.5,3.0$, and 4.3 $\mathrm{mM}$, respectively. Plasma glucose concentrations were obtained within $5 \mathrm{~min}$ in every sample. While awaiting further analysis, the remaining plasma samples were frozen at $-70^{\circ} \mathrm{C}$.

For studies of isotopic enrichment, proteins were precipitated from plasma by addition of equal amounts of $3 \mathrm{M}$ perchloric acid (6). After centrifugation, the supernatant was neutralized with $20 \% \mathrm{KOH}$ solution and subjected to sequential anion and cation exchange chromatography (6). The eluate was evaporated in a vacuum centrifuge (A 160 Speed Vac Concentrator, Savant Instruments Inc, Farmingdale, NY) at $70^{\circ} \mathrm{C}$. The remaining material was dissolved in pyridine and treated with butaneboronic acid and acetic anhydride for preparation of the dibutaneboronate acetate derivative of glucose $(6,14)$. The $6,6{ }^{2} \mathrm{H}_{2-}$ glucose isotopic enrichment in plasma was measured by gas chromatography/mass spectrometry in the electron impact mode. The instrument used was a Finnigan SSQ 70 mass spectrometer (Finnigan MAT, San José, CA) equipped with a Varian gas chromatograph (Varian Associates Inc, Sunnyvale, CA) with a DB-17 capillary column $(30 \mathrm{~m} \times 0.32 \mathrm{~mm})$. The temperature of the oven was set at $220^{\circ} \mathrm{C}$, and the electron energy used was $70 \mathrm{eV}$. Selective ion monitoring of the M-57 ion $(\mathrm{m} / \mathrm{z} 297)$ and

Table 2. Infusion rate of labeled and unlabeled glucose, total amount of oral feeding, and time without oral feeding before the study

\begin{tabular}{|c|c|c|c|c|c|c|c|}
\hline Patient no. & $\begin{array}{l}\text { Isotope infusion } \\
\left(\mathrm{mg} \cdot \mathrm{kg}^{-1} \cdot \mathrm{min}^{-1}\right)\end{array}$ & $\begin{array}{l}\text { Glucose infusion } \\
\left(\mathrm{mg} \cdot \mathrm{kg}^{-1} \cdot \mathrm{min}^{-1}\right)\end{array}$ & $\begin{array}{l}\text { Oral } \\
\text { feeding } \\
(\mathrm{mL})\end{array}$ & $\begin{array}{l}\text { Time with no } \\
\text { oral feeding } \\
\text { (h) }\end{array}$ & $\begin{array}{c}\text { GPR } \\
\left(\mathrm{mg} \cdot \mathrm{kg}^{-1} \cdot \mathrm{min}^{-1}\right)\end{array}$ & $\underset{\left(\mathrm{mg} \cdot \mathrm{kg}^{-1} \cdot \mathrm{min}^{-1}\right)}{\mathrm{Ra}}$ & $\begin{array}{l}\text { P-glucose } \\
(\mathrm{mM})^{*}\end{array}$ \\
\hline 1 & 0.11 & 1.9 & 7.0 & 2.0 & 6.7 & 8.7 & 3.1 \\
\hline 2 & 0.14 & 2.6 & 2.0 & 6.0 & 4.3 & 7.1 & 3.9 \\
\hline 3 & 0.23 & 2.3 & 3.0 & 3.5 & 7.4 & 9.9 & 4.1 \\
\hline 4 & 0.14 & 1.4 & 1.0 & 4.5 & 7.8 & 9.3 & 4.8 \\
\hline 5 & 0.11 & 0.0 & 2.0 & 3.5 & 7.4 & 7.5 & 2.1 \\
\hline 6 & 0.11 & 0.0 & 1.0 & 12.0 & 5.8 & 5.9 & 2.6 \\
\hline 7 & 0.15 & 1.4 & 6.0 & 2.0 & 7.0 & 8.6 & 7.0 \\
\hline 8 & 0.15 & 1.5 & 6.0 & 0.3 & 6.6 & 8.3 & 4.3 \\
\hline 9 & 0.12 & 1.6 & 0.0 & - & 3.4 & 5.2 & 2.8 \\
\hline 10 & 0.14 & 1.7 & 1.0 & 15.0 & 4.6 & 6.4 & 2.9 \\
\hline Mean $\pm \mathrm{SD}$ & $0.14 \pm 0.04$ & $1.4 \pm 0.9$ & $2.9 \pm 2.5$ & $5.4 \pm 4.9$ & $6.1 \pm 1.5$ & $7.7 \pm 1.5$ & $3.8 \pm 1.4$ \\
\hline
\end{tabular}

* P-glucose, mean plasma glucose concentration during steady state. 
the corresponding $M+2$ ion ( $\mathrm{m} / \mathrm{z}$ 299), reflecting unlabeled and labeled glucose, was performed (15). To calculate the isotopic enrichment (given as labeled/unlabeled glucose in \%) in individual samples, a standard curve was used. This was obtained by gradually increasing the amount of dideuteroglucose in relation to unlabeled glucose. The analytical error of the gas chromatography/mass spectrometry method determined as the $C V \pm \mathrm{SD}$ in duplicate samples $(n=44)$ was $3.1 \pm 1.4 \%$.

When the concentrations of glucose and isotopic enrichments in the plasma remained approximately constant $(\mathrm{CV}<11 \%)$ (16). they were considered to be at steady state. In the infants not receiving unlabeled glucose (nos. 5 and 6 ). this criterion was not fulfilled as to isotopic enrichment $(\mathrm{CV}=13.3$ and $15.8 \%$, respectively) and as to plasma glucose concentration in infant no. $5(\mathrm{CV}=11.9 \%)$ (17) (Fig. 1). At steady state, the disappearance rate of glucose equals the $\mathrm{Ra}$ in the sampled plasma pool (2). Ra is the sum of the GPR, the rate of i.v. infusion of labeled and unlabeled glucose, and the rate of enterohepatic glucose entry. The amounts of breast milk given to our patients were minimal (see description of subjects and Table 2). Thus, any possible contribution of enterohepatic glucose was disregarded in the calculations of GPR. During the periods of steady state,

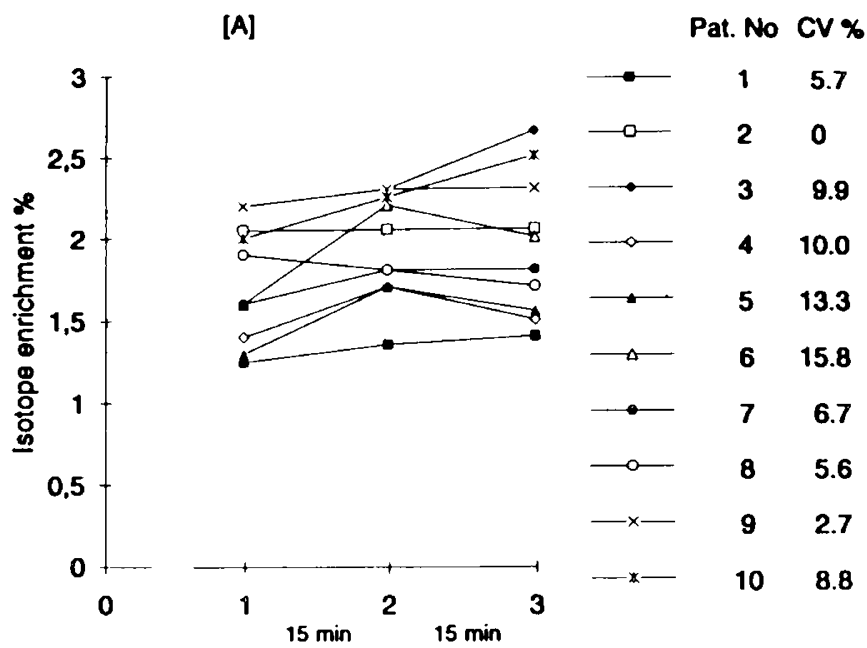

[B]

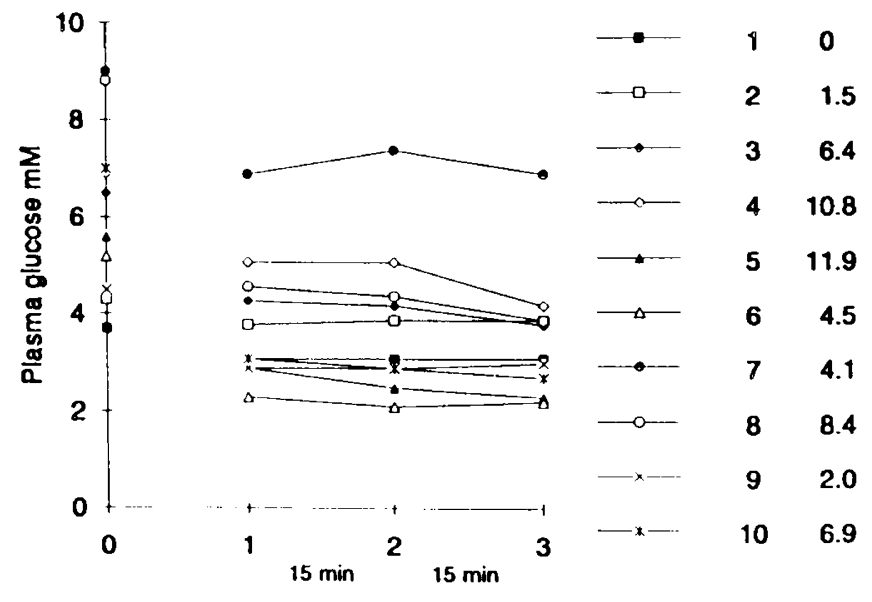

Fig. 1. Isotope enrichments (given as labeled/unlabeled glucose in (a). A. plasma glucose concentrations: $B$. corresponding $C V$ during the steady state periods $(l-3)$ for individual patients. the GPR was calculated in the following way:

$$
\mathrm{GPR}=(\mathrm{i} \times 100 / \mathrm{IE})-\mathrm{GIR}
$$

where GPR is expressed in $\mathrm{mg} \cdot \mathrm{kg}^{-1} \cdot \mathrm{min}^{-1}, \mathrm{i}$ is the infusion rate of labeled glucose $\left(\mathrm{mg} \cdot \mathrm{kg}^{-1} \cdot \mathrm{min}^{-1}\right)$. IE is the isotopic enrichment given as labeled/unlabeled glucose (\%), and GIR is the infusion rate of unlabeled glucose $\left(\mathrm{mg} \cdot \mathrm{kg}^{-1} \cdot \mathrm{min}^{-1}\right)$.

Statistical analysis. Simple linear regression analysis was used to calculate statistical significance for various parameters related to GPR and $\mathrm{Ra}$. A $p$ value of $<0.05$ was considered significant. The agreement between the methods for determination of plasma glucose was assessed according to Bland and Altman (13).

\section{RESULTS}

Approximate steady state regarding the concentration and isotopic enrichment of plasma glucose was attained $68 \pm 14 \mathrm{~min}$ (mean $\pm \mathrm{SD}$ ) (range $45-90 \mathrm{~min}$ ) after the start of the constant infusion of $\mathrm{D}-6,6-{ }^{2} \mathrm{H}_{2}$-glucose. The steady state period lasted for $30-60 \mathrm{~min}$. No episodes of hypoglycemia (plasma glucose $\leq 1.6$ $\mathrm{mM}$ ) or other complications occurred during the study periods. The mean plasma glucose concentrations during steady state are shown in Table 2 . The mean $\mathrm{Ra}( \pm \mathrm{SD})$ was $7.7 \pm 1.5 \mathrm{mg} \cdot \mathrm{kg}^{-1}$. $\min ^{-1}$ (range 5.2-9.9), and the mean GPR $( \pm$ SD) was $6.1 \pm 1.5$ $\mathrm{mg} \cdot \mathrm{kg}^{-1} \cdot \mathrm{min}^{-1}$ (range 3.4-7.8) (Table 2). Neither Ra nor GPR. per $\mathrm{kg}$ body weight or total, was significantly related to body weight, mean plasma glucose level, gestational age. postnatal age. or glucose infusion rate during the study period or to the length of time without oral feeding or the amount of breast milk given before the study.

\section{DISCUSSION}

The results of this study show that extremely immature infants, born after 25 to $26 \mathrm{wk}$, have a capacity for glucose production as early as their first $24 \mathrm{~h}$ of life. The GPR found in these infants were in fact close to or even higher than the rates reported earlier $(5-8,19-21)$ for less immature infants. Bier et al. (6) found mean values for GPR in infants with gestational ages of 27 to $40 \mathrm{wk}$ that were in accordance with those obtained in the present study. However, the infants in their study were examined after the 1st $\mathrm{d}$ of life and included only one infant with a gestational age of less than $28 \mathrm{wk}$. In term and near-term infants investigated during the first $3 \mathrm{~d}$ postnatally, Kalhan et al. $(5,7,20)$. Denne and Kalhan $(21)$, and Cowett et al. $(18,19)$ reported values for GPR that are close to or somewhat lower than those in the present study. Both our values for GPR and those referred to above $(5-7,18-21)$ were higher than the values reported by Baarsma $e t a l .(8)$ in a recent study of growth-retarded infants with gestational ages of 30 to $40 \mathrm{wk}$. On the basis of extrapolation from an observed linear relationship between GPR and birth weight as well as gestational age in that study, it was suggested that infants with a gestational age of about $25 \mathrm{wk}$ and birth weight of about $800 \mathrm{~g}$ might lack glucose production. The low values for GPR reported in that study (8) may be explained by a suppressive influence of comparatively large amounts of exogenous glucose given during the study period. It is known from studies in adults that on glucose administration the hepatic GPR decreases $(5,19)$. This regulatory effect is probably mediated by insulin (5). There have been some investigations on the influence of exogenous glucose on GPR in newborn infants. In two studies by Cowett et al. $(4,19)$, it was shown that glucose infusion at a mean rate of $6 \mathrm{mg} \cdot \mathrm{kg}^{-1} \cdot \mathrm{min}^{-1}$ totally suppressed or decreased GPR in the majority of both term and preterm infants. Kalhan et al. (5) reported that the glucose production was partially suppressed by glucose infusion at a rate of $4.6 \mathrm{mg} \cdot \mathrm{kg}^{-1} \cdot \mathrm{min}^{-1}$ in both term and preterm infants. The infants of our study were given no or only low doses of glucose. Calculations of GPR in patients 1 to 4 , studied during administration of a low dose of glucose. clearly showed that these infants were able to produce glucose at rates similar to or even exceeding those reported earlier 
in term newborn infants $(5-7,18-21)$. We therefore considered it possible to study the GPR without glucose or during infusions of only small amounts, provided that the plasma glucose levels were measured frequently. The purpose was to find out the minimum amount of exogenous glucose needed to attain a steady state level while still avoiding hypoglycemia. Two of the patients (nos. 5 and 6) received only deuterated glucose for $2 \mathrm{~h}$. In both of them, the plasma glucose concentration decreased gradually but did not fall below $2.0 \mathrm{mM}$. Approximate steady state was present during $30 \mathrm{~min}$ of these study periods, although the $\mathrm{CV}$ regarding the isotopic enrichment and the plasma glucose concentration was higher than in the other eight patients (17). The results show that extremely immature infants, in the absence of an i.v. glucose infusion, are capable of producing glucose at least during a limited period of time. This finding can be of clinical importance, because immature infants may occasionally lack glucose support under routine conditions, e.g. during accidental interruptions of the i.v. access.

In contrast to the patients studied by Baarsma et al. (8), most of the infants in our study as well as in most earlier studies (57. 19-21) had received some oral feeding before the study. In those studies (5-7, 19-21), the quantities were not specified. In regard to the present study, it is unlikely that the contribution of monosaccharides from breast milk would have influenced the GPR to any significant extent, inasmuch as the volumes were small and were distributed over several hours before the study (see Table 2). One patient (no. 9) had not received any oral feeding at all, and in two patients (nos. 8 and 10) oral feeding had not been given for 12 and $15 \mathrm{~h}$, respectively, before the start of the study. The GPR in these three patients did not differ from those in the other patients.

In our study, no correlations were found between GPR and birth weight or gestational age. This may be partly explained by the homogeneity of the study group with regard to these variables.

The occurrence of glucose production in very immature newborn infants demonstrates a capacity for glycogenolysis and/or gluconeogenesis. Our data support the assumption made by Girard (22) that it is the birth process itself rather than the developmental stage that is responsible for the induction of gluconeogenetic enzymes. It is not possible to distinguish between the contribution of glycogenolysis and that of gluconeogenesis to the glucose production in the present study. Because most of the infants were investigated between the ages of 10 and $24 \mathrm{~h}$, their small glycogen stores were probably depleted (2). Consequently, the glucose production was likely to have depended mostly on gluconeogenesis. The rather short steady state periods may indicate that the supply of substrates for glucose production was limited. It has been shown that the liver in the newborn infant has to be supplied with sufficient amounts of gluconeogenetic substrates to maintain a high rate of gluconeogenesis (22). All infants in the present study were of approximately the same gestational age. In spite of this, the rate of glucose production varied. This variation might be explained by differences in birth weight in relation to gestational age, respiratory illness, and treatment with theophylline as well as pre- and perinatal factors such as maternal disease or maternal pharmacologic treatment with tocolytic agents $(23,24)$.

Acknowledgments. The authors thank Elisabeth Söderberg and Svante Zillén for skillful laboratory and technical assistance.

\section{REFERENCES}

1. Ogata ES 1986 Carbohydrate metabolism in the fetus and neonate and altered neonatal glucoregulation. Pediatr Clin North Am 33:25-45

2. Bougnères PF 1987 Stable isotope tracers and determination of fuel fluxes in newborn infants. Biol Neonate 52:87-96

3. Senior B, Wolsdorf JI 1979 Substrates, gluconeogenesis and hypoglycaemia in children. Pediatr Clin North Am 26:171-185

4. Cowett RM, Susa JB, Oh W, Schwartz R 1984 Glucose kinetics in glucoseinfused small for gestational age infants. Pediatr Res 18:74-79

5. Kalhan SC, Oliven A, King K, Lucero C 1986 Role of glucose in the regulation of endogenous glucose production in the human newborn. Pediatr Res 20:49-52

6. Bier DM. Leake R, Haymond M. Arnold K, Gruenke L. Sperling M, Kipnis D 1977 Measurement of "true" glucose production rates in infancy and childhood with 6,6-dideuteroglucose. Diabetes 26:1016-1022

7. Kalhan SC, Bier DM, Savin SM 1980 Estimation of glucose turnover and ${ }^{13} \mathrm{C}$ recycling in the human newborn by simultaneous $1-{ }^{13} \mathrm{C}$ glucose and $6,6-{ }^{2} \mathrm{H}_{2}$ glucose tracers. J Clin Endocrinol Metab 50:456-460

8. Baarsma R, Chapman T, van Asselt W. Berger R, Okken A 1990 Glucose kinetics in pre-term and near-term small for gestational age newborn infants. In: Chapman TE, Berger R, Reingoud DJ (eds) Stable Isotopes in Paediatric Nutritional and Metabolic Research. Intercept Limited, Andover, MA. pp $123-132$

9. Finnström O 1977 Studies on maturity in newborn infants. IX. Further observations on the use of external characteristics in estimating gestational age. Acta Paediatr Scand 66:601-604

10. Dubowitz LMS, Dubowitz V, Goldberg C 1970 Clinical assessment of gestational age in the newborn infant. $J$ Pediatr $77: 1-10$

11. Barness LA 1981 Nutritional requirements of the full-term neonate. In: Suskin RM (ed) Textbook of Pediatric Nutrition. Raven Press Books Ltd. New York, pp 21-28

12. Food and Drug Administration 1987 Guideline on validation of the Limulus amebocyte lysate test as end-product endotoxin test for human and animal parenteral drugs, biological products and medical devices. Food and Drug Administration, Washington. DC

13. Bland MJ. Altman DG 1986 Statistical methods for assessing agreement between two methods of clinical measurement. Lancet 1:307-310

14. Wiecko J, Sherman W 1976 Boroacetylation of carbohydrates. Correlations between structure and mass spectral behavior in monoacetylhexose cyclic boronic esters. J Am Chem Soc 98:7631-7637

15. Bier DM, Arnold KJ, Sherman WR. Holland WH. Holmes WF. Kipnis DM 1977 In vivo measurement of glucose and alanine metabolism with stable isotope tracers. Diabetes 26:1005-1015

16. Bougnères PF, Karl IE, Hillman LS, Bier DM 1982 Lipid transport in the human newborn. Palmitate and glycerol turnover and the contribution of glycerol to neonatal hepatic glucose output. J Clin Invest 70:262-270

17. Bougnères PF, Lemmel C, Ferrè P, Bier DM 1986 Ketone body transport in the human neonate and infant. J Clin Invest 77:42-48

18. Cowett RM, Susa JB, Giletti B, Oh W, Schwartz R 1983 Glucose kinetics in infants of diabetic mothers. Am J Obstet Gynecol 146:781-786

19. Cowett RM, Oh W, Schwartz R 1983 Persistent glucose production during glucose infusion in the neonate. J Clin Invest 71:467-475

20. Kalhan SC, Savin SM. Adam AJ 1976 Measurement of glucose turnover in the human newborn with glucose- $1-{ }^{13} \mathrm{C}$. J Clin Endocrinol Metab 43:704707

21. Denne SC. Kalhan SC 1986 Glucose carbon recycling and oxidation in human newborns. Am J Physiol 51:71-77

22. Girard J 1990 Metabolic adaptation to change of nutrition at birth. Biol Neonate 58:3-15

23. Epstein MF, Nicholls RN. Stubblefield PG 1979 Neonatal hypoglycaemia after beta-sympathomimetic tocolytic therapy. J Pediatr 94:449-453

24. Cowett R 1985 Pathophysiology, diagnosis and management of glucose homeostasis in the neonate. In: Lockhart JD (ed) Current Problems in Pediatrics. Year Book Medical Publishers, Chicago, pp 6-47 